\title{
ASSESSMENT OF MICROPLASTICS IN THE ENVIRONMENT - FIBRES: THE DISREGARDED TWIN?
}

\author{
Benjamin Piribauer *, Thomas Laminger, Wolfgang Ipsmiller, Daniel Koch and Andreas Bartl \\ TU Wien, Institute of Chemical, Environmental and Bioscience Engineering, Getreidemarkt 9/166, 1060 Vienna, Austria
}
Article Info:
Received:
15 July 2019
Revised:
21 October 2019
Accepted:
23 October 2019
Available online:
6 December 2019
Keywords:
Microplastic
Environmental pollution
Polymer particle and fibre
Particle analysis
Contamination assessment

\begin{abstract}
The pollution of plastics into the environment is considered one of the major challenges of the current century. In particular, microplastic pollution is considered a significant threat to both human and animal life since removal is almost impossible once these plastic particles make their way into the environment. Unfortunately, when scholars evaluate microplastic contamination in the environment, synthetic fibres are often disregarded. This approach is flawed, considering that a large part of clothing consists purely of synthetic fibres, meaning they are omnipresent in every part of human activities along with emissions. This work takes a critical view of state-of-the-art analysis methods for microplastics in soil, water and air, with a special focus on their ability (or inability) to detect fibrous materials. A case study in the form of a critical evaluation was carried out to highlight common problems when detecting microplastic fibres, focusing primarily on the sampling of large volumes of water. Another case study explores microscopy as a means to analyse solid specimens regarding microplastic contamination. Furthermore, the sources of fibre pollution and the pathways they take in the environment before ending up in the maritime system are explored. Finally, this work aims to create and enforce standardised methods addressing microplastic pollution, which would potentially solve many of the current associated problems.
\end{abstract}

\section{INTRODUCTION}

One of the major challenges of this century is environmental pollution. In recent years, the scientific community has also focused on microplastics. While increasing efforts are taken in sampling and identification methods, microplastics seem to be found nearly everywhere - in soil, water, air, food and even purified drinking water (Pivokonsky et al., 2018). Every place humans have touched, we have left behind our presence in the form of these tiny microplastic particles and fibres. Even in remote places, such as glacier regions (Ambrosini et al., 2019), these particles have been found before. It is probably even possible that we left behind microplastics at the 1969 moon landing. Now that we have reached Mars, it is possible one could even say with some tongue-in-cheek humour that our microplastic problem has reached the interplanetary scale. However, apart from jokingly considering plastic waste in space, NASA has been considering using plastic waste to compress and immobilize garbage in spacecrafts (Fisher et al., 2008).

One of the first indications of terrestrial plastic pollution in sea water dates back to 1972 (Carpenter \& Smith, 1972). The authors sampled particles in the size range be- tween 2.5 and $5 \mathrm{~mm}$ from the Sargasso Sea surface. The term "microplastics" itself was mentioned in 2004 (Thompson et al., 2004) without, however, specifying a size range. On the one hand, the authors found granular material. On the other hand, the major fraction turned out to be fibrous and approximately $20 \mu \mathrm{m}$ in diameter. Since then, a large number of studies have been published, but there is no common agreement about the size range of microplastics (Hidalgo-Ruz, Gutow, Thompson, \& Thiel, 2012). Even if it has been suggested to define microplastics as particles below $5 \mu \mathrm{m}$ (Arthur, Baker, \& Bamford, 2009), an elaborate review revealed that the particle size of microplastics ranges between $1 \mu \mathrm{m}$ and $20 \mathrm{~mm}$ for sediment particles and 0.5 to $29 \mathrm{~mm}$ for sea surface particles (Hidalgo-Ruz et al., 2012). The German Umweltbundesamt (Miklos, Obermaier, \& Jekel, 2016) suggested using the terms listed in Table 1 to specify plastics in the environment in regard to their size, including nanoparticles (Comission, 2011). According to this definition, microplastics are smaller by a power of ten compared to the abovementioned $5 \mathrm{~mm}$ as an upper limit. However, the Austrian Umweltbundesamt distinguishes between large ( 1 to $5 \mathrm{~mm}$ ) and small $(1 \mu \mathrm{m}$ to $1 \mathrm{~mm}) \mathrm{mi}-$ croplastic particles (Liebmann, 2015). Again, the sugges- 
TABLE 1: Definition of microplastics as suggested by the German Umweltbundesamt c.

\begin{tabular}{l|l}
\hline Term for & size range \\
\hline Macroplastics & $>5 \mathrm{~mm}$ \\
\hline Mesoplastics & 0.1 to $5 \mathrm{~mm}$ \\
\hline Microplastics & 0.1 to $100 \mu \mathrm{m}$ \\
\hline Nanoplastics & $<100 \mathrm{~nm}$ \\
\hline PE & $<0.5$ \\
\hline PS & $<0.5$ \\
\hline
\end{tabular}

According to the EU definition of nanoparticles (Comission, 2011).

tions differ by an order of magnitude.

The quantification of microplastics is handled just as inconsistently as the size range is handled. As shown in an elaborate review (Hidalgo-Ruz et al., 2012), microplastics are not only quantified as a number of items $(-)$ or mass (g) but they can also be related to the area $\left(\mathrm{m}^{2}\right)$, volume $\left(\mathrm{m}^{3}\right)$, length of strandline $(\mathrm{m})$ or mass of sediment $(\mathrm{kg})$.

Even if a large number of studies are available, it is more or less impossible to compare results from different sources. A well-accepted standardization of sizes and units in the field of microplastics on an international level is a prerequisite for making any study results comparable.

In principle, one can distinguish between two types of microplastics, primary and secondary (Miklos et al., 2016). Primary microplastics are produced intentionally in small sizes for certain products, such as cosmetic products or detergents and cleaners. Secondary microplastics are generated from larger particles (macroplastics and mesoplastics) by physical, biological and chemical degradation.

There are many ways these microplastics may be emitted into the environment. For example, microplastics can end up in the maritime system through littering or by rain and flushing into rivers (GESAMP, 2015). These small particles are likely to be ingested by animals and will accumulate in the food chain, and then eventually in human food (Hantoro, Lohr, Van Belleghem, Widianarko, \& Ragas, 2019). Most polymers in plastics are not a risk to human health directly and will likely just pass through the gastrointestinal system; however, the toxic additives in or adsorbed to the plastic materials may potentially leach out, be stored in tissue, accumulate and reach harmful levels (Carbery, O'Connor, \& Palanisami, 2018). As these particles present a large surface area, they are also able to amass "persistent organic pollutants" (POPs), such as pesticides, industrial chemicals and burning residues from the environment. Therefore, while the materials themselves are harmless, additives and POPs may harm humans and the biosphere (Hantoro et al., 2019). This issue is well known, but the concrete impact on human health is not yet fully understood. However, the precautionary principle obligates us to search for solutions immediately.

Microplastics can enter the human body through the food chain; however, they can also enter the human body through the respiratory system. Fine particulate dust consists of a broad spectrum of materials. In particular, rubber particles, which are a large part of the dust fraction, can be considered microplastics (Liebmann, 2015). These rubber plastics, and other fibrous materials, are likely to be bio-persistent; however, most of them are suspected to be mucociliary clearable. Nevertheless, they may persist in the lungs and could cause long-term health effects (Gasperi et al., 2018).

There was major public disapproval when the issue of microplastics in cosmetic products, such as shampoos and toothpastes, was revealed for the first time, resulting in many companies committing to product changes (Park, 2016). On the other hand, the emission of plastic fibres through, for example, washing machines has yet to receive the same amount of attention, despite being even more relevant based on the emitted masses of microplastics. Based on a recent study in Germany, microplastics in cosmetic products account for $19 \mathrm{~g} /\left(\right.$ cap $\left.^{*} \mathrm{a}\right)$, while fibre emissions from clothing accounts for $77 \mathrm{~g} /\left(\right.$ cap $\left.^{\star} a\right)$ (Bertling, Hamann, \& Bertling, 2018). Examining the instruction manual for a popular brand of washing machine, it is even suggested to just rinse the fibres out of the filter after it gets too clogged (Miele, 2019). Fibres are not officially disregarded in scientific research, but due to the ability of fibres to easily pass through sieves with wider meshes, they are often not detected, as described in the next paragraphs.

There is quite a broad spectrum of materials and morphologies applied when discussing fibres. Fibres used for textiles and clothing, which represent their major applications, are almost exclusively composed of polymers. In 2018, global fibre production reached 105.6.106 $\mathrm{t}$ (Chemiefaser, 2018). On the one hand, so-called natural fibres are derived from crops or animals. The most prominent representative natural fibre is cotton, with a volume of 26.9.106 $\mathrm{t}$ in 2018 (Council, 2018), based on the natural polymer cellulose. On the other hand, fibres can originate from technical processes, so-called man-made fibres, regardless of their material origin. Both natural (mainly cellulose) and synthetic polymers (e.g., polyester, polyamide, polypropylene, etc.) are used (BISFA, 2017). The volumes of fibres based on synthetic polymers are much higher (66.6.106 $\mathrm{t}$ in 2018 (Chemiefaser, 2019a) compared to fibres based on cellulose (6.8.106 $t$ in 2018; (Chemiefaser, 2019a)). It should be further considered that among synthetic polymer fibres, PET plays a predominant role. In 2017, 53.7.106 t of PET fibres (Chemiefaser, 2019b) was produced, which means a share of $82.7 \%$ compared to a total of $64.9 \cdot 106 \mathrm{t}$ (Chemiefaser, 2019a) of synthetic polymer fibres.

Both fibre categories, man-made and natural, that are based on cellulose origins are biodegradable (Sular \& Devrim, 2019). These fibres do not represent any specific threat to the environment and do not account for microplastics. However, considering synthetic polymer fibres only, the potential of these fibres being released into the environment is 66.6.106 $t$ annually (Chemiefaser, 2019a). This represents a large volume, however, it is a smaller amount than the total amount of plastics, which reached 348.106 t in 2017 (PlasticsEurope, 2018). As mentioned above, it must also be considered that PET is by far the predominant polymer $(53.7 \cdot 106 \mathrm{t}$ or $83 \%$ (Chemiefaser, 2019b)), while $53 \%$ (i.e., 184.106 t) of total plastics are polyolefins (Prata, 2018). 
However, no generally valid statements can be made about fibres released into the environment, as fibres can be present in different forms. Table 2 shows different terms for fibrous structures, and it provides an estimation of their potential to release microplastics into the environment. As the chance for environmental pollution increases, the shorter and thinner the fibres are. The situation is, however, even more complex because fibres in textiles can be damaged due to abrasion (Textor, Derksen, Bahners, Gutmann, \& Mayer-Gall, 2019) during their use and can then emit plastics into water (washing machines) or air.

\section{ASSESSMENT METHODS}

"The four basic factors which affect the quality of environmental data are sample collection, sample preservation, analyses and recording" (US Environmental Protection Agency, 1982). Although sampling guidelines have existed for more than 40 years, there are still improper actions in several areas of microplastics assessment, which may result in questionable conclusions derived from insufficient data. Hence, there is still a need for new methods and guidelines on sampling, preservation and analysis that address the specific characteristics of microplastics (GESAMP, 2015; Prata, da Costa, Duarte, \& Rocha-Santos, 2019). Sample collection has the biggest impact on generating correct and reproducible results, however, no proper guidelines exist, and most works seemingly developed "their" methods through adaption to the specific sampling problem. Therefore, it is very hard to suggest a proper method that addresses every research case. However, the analysis of the samples can possibly be standardized, and that is the main topic of this work.

\subsection{Solid samples}

After sampling, it is important to separate the microplastic particles from other materials in the specimen. Mostly, methods such as optical-haptic separation, sinkfloat separation, flotation, sieving and chemical etching are used. Depending on the sample, the order of these procedures can vary from case to case. A review of the related literature shows that the analysis method of choice seems to be based on sink-float separation with additional chemical treatment beforehand or afterwards to eliminate organic components. Afterwards, the remaining plastic particles are usually identified with spectroscopic methods (D. He et al., 2018; Mai, Bao, Shi, Wong, \& Zeng, 2018; Prata et al., 2019).
An exemplary process could consist of dispensing the sample in a heavy liquid, resulting in the separation of the floating plastic particles from sand and earth. Then, the floating particles are filtered from the liquid. Afterwards, the particles are weighed and analysed by a light microscope and/or near infrared spectroscopy. To assess heavy polymeric materials, such as polyesters (density $\sim 1.4 \mathrm{~g} /$ $\mathrm{cm}^{3}$ ), solutions need to have a significantly higher density. Unfortunately, the liquids used are often very expensive and potentially toxic, or they have a density very close to $1.4 \mathrm{~g} / \mathrm{cm}^{3}$. Furthermore, different publications use different separation fluids, which makes comparison problematic. Considering that polyesters are the most widely used polymers in fossil-based plastics or in synthetic fibres (Eyerer, Hirth, \& Elsner, 2008), it is even more important to put a greater degree of effort into the development of new separation methods.

Agglomeration, biofouling and small particle sizes, in general, can be problematic. Air bubbles and/or agglomerates with plastic fibres may even float sand particles that are denser than the separation liquid or they may, vice versa, sink the plastic particles (see Figure 1). Thus, this step seems to be very critical. In addition to adding surfactants to limit these effects to a certain extent, ultrasonic treatment, for example, could be another option since its effectiveness for breaking agglomeration has been shown in other cases (Kusters, Pratsinis, Thoma, \& Smith, 1993).

\subsection{Liquid Samples}

Analysis methods for liquid samples are mainly used to assess microplastics within samples from rivers, lakes, seas, sewage treatment effluents and washing machine wastewater outlets. The state-of-the-art techniques use sieving as the primary step with additional chemical treatment afterwards or even as the sole procedures for liquid samples (Napper \& Thompson, 2016; Pirc, Vidmar, Mozer, \& Krzan, 2016; Sun, Dai, Wang, van Loosdrecht, \& Ni, 2019; Talvitie, Mikola, Koistinen, \& Setala, 2017; Talvitie, Mikola, Setala, Heinonen, \& Koistinen, 2017; Ziajahromi, Neale, Rintoul, \& Leusch, 2017).

However, using sieving or filtration processes on particles and fibres is rather complex when a vast amount of water needs to be analysed because of low particle concentrations. Generally, there are two major challenges in using sieve analysis, namely, the choice of proper mesh sizes and the guarantee for a sufficient amount of accuracy of the mesh geometry. A multiple sieve stack will pro-

TABLE 2: Terms to specify different types of fibres according to their morphology (BISFA, 2017).

\begin{tabular}{|c|c|c|}
\hline Term & Definition & Remarks in regard to relevance to microplastics \\
\hline Filament & A fibre of very great length & Most likely not released during normal use or washing \\
\hline Staple fibre & Textile fibre of limited but spinnable length & $\begin{array}{l}\text { Release during normal use or washing possible; too large to be } \\
\text { airborne }\end{array}$ \\
\hline Flock & Very short fibres, intentionally produced for other purposes & Risk to be released during normal use or washing \\
\hline Fibril & A subdivision of a fibre can be attached to the fibre or loose & $\begin{array}{l}\text { High risk to be released during normal use or washing; loose } \\
\text { fibrils most likely airborne }\end{array}$ \\
\hline Fibre fly & $\begin{array}{l}\text { Airborne fibres or parts of fibres (light enough to fly), visible as } \\
\text { fibres to the human eye }\end{array}$ & $\begin{array}{l}\text { Extreme high risk to be released during normal use or washing } \\
\text { airborne by definition }\end{array}$ \\
\hline
\end{tabular}




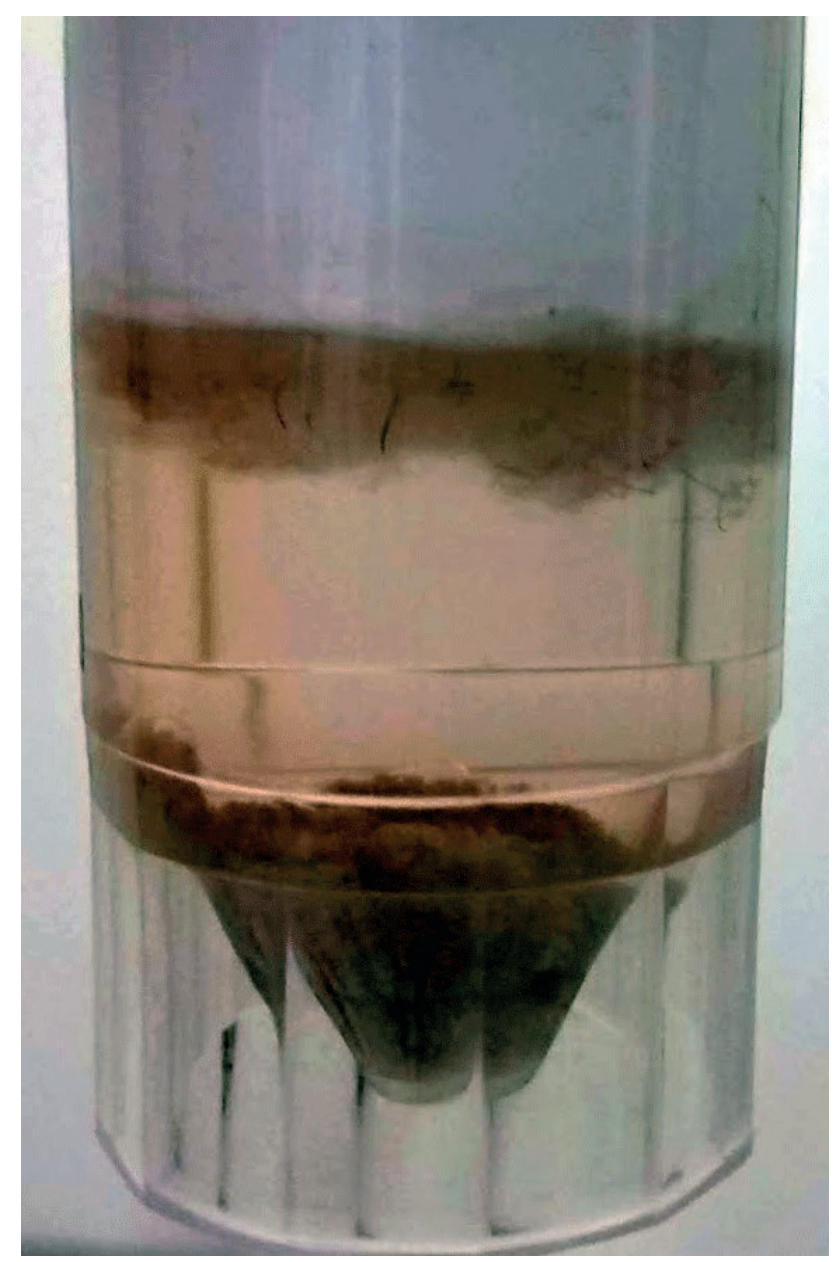

FIGURE 1: Partially floating quartz sand commingled with added polyester fibres and polypropylene granulate (model mixture) after sink-float separation in a heavy liquid; separation efficiency poor although accurate adjustment of density.

vide a more precise size analysis but proportionally lower material quantities at each mesh, leading to uncertainties during weighing. The second issue is particle deposition on the mesh surface, which can cause time-dependent changes in separation characteristics (see Figure 2). Often, even a small amount of material deposited on a sieve leads to blocking and a high pressure drop. This is particularly true for small mesh sizes. Thus, sieves featuring narrow meshes are often neglected. Consequently, a compromise must be found in sieve analysis between throughputs and measurement accuracy.

Microplastics in the aquatic environment have been studied extensively using these sieve analyses. Different sampling techniques and the use of sieves with different mesh sizes in particular result in data sets that are not comparable. Although many studies vary in sampling methods, some general statements can be made. The smaller the sieve mesh sizes are, the higher the amounts (or masses) of microplastics particles and fibres found (Murphy, Ewins, Carbonnier, \& Quinn, 2016; Napper \& Thompson, 2016; Talvitie, Mikola, Koistinen, et al., 2017; Talvitie, Mikola, Setala, et al., 2017; Ziajahromi et al., 2017). Regarding small fibre fragments (or flakes), such fragments were de- tected only where the authors used sieves of a mesh size of $25 \mu \mathrm{m}$ or smaller for their experiments (Adam, Yang, \& Nowack, 2019). High amounts of short fibres arise from textile handling, such as machine washing and tumble-drying. Here, the mass of fibres found on a 200- $\mu$ m sieve was only a few milligrams (Pirc et al., 2016). Other studies on the washing of synthetic jackets, however, retrieved up to 2 $\mathrm{g}$ of fibres in a sieve stack with 333- $\mu \mathrm{m}$ and $20-\mu \mathrm{m}$ screens (Hartline et al., 2016).

\subsection{Air Samples}

Be it in the office, outdoors next to a busy street, or in the countryside far from urban areas, microplastic fibres are steadily present in the air with varying concentrations. With every breath we take, we also inhale small amounts of these fibres into our respiratory system. We can ingest them even with the food we consume since these tiny particles can easily agglomerate on the food's surface (Gasperi et al., 2018).

Inside the human body, these fibres can penetrate deep into the lung, resulting in impaction and clearance problems. Fibres with lengths up to $250 \mu \mathrm{m}$ were already found inside the deeper regions of the human lung (Prata, 2018). Due to their large surface areas, the deposited fibres are able to interact with organic material, which makes their removal by the human body complicated, and they may also release hazardous substances, such as the POPs addressed in the introduction (Rochman, 2015). Therefore, it is important to properly detect high-risk areas where the fibre and dust concentrations, or intake levels, become critical, e.g., in industrial environments, or when exposed to them for extended periods, such as in offices or even at home in bedrooms. For example, for those involved in the fibre production industry, the amount of lung disease is alarmingly high and it is significantly higher than for the rest of the population (Prata, 2018).

However, microplastic pollution from air has been discussed only in recent years. Air samples are usually obtained by standardised air samplers (PM10 high volume air samplers or small personal samplers) using absolute filter media to separate any particulate matter from the air flow throughput (Gasperi et al., 2018). To date, multiple studies have been able to detect fibrous materials in different environments. Microscopic and spectroscopic techniques were used afterwards to differentiate shape, e.g., fibres and particles, and the material, e.g., synthetic and natural. It was found that urban sites reach particle deposition rates up to 355 particles/mday, whereas suburban sites experience only approximately a third of that value (Rachid Dris, Gasperi, Saad, Mirande, \& Tassin, 2016).

Additionally, assessment methods to determine indoor and outdoor fibre concentrations using vacuum cleaners are important. Settled dust was collected from the floor, and the captured dust specimens are then analysed by density separation techniques, as described in the previous chapter. Indoor fibre concentrations of approximately 1 to 60 fibres $/ \mathrm{m}^{3}$ and outdoor fibre concentrations of approximately 0.3 to $1.5 \mathrm{fibre} / \mathrm{m}^{3}$ were found (R. Dris et al., 2017). An interesting result is that only approximately onethird of the indoor dusts were actually synthetic materials. 


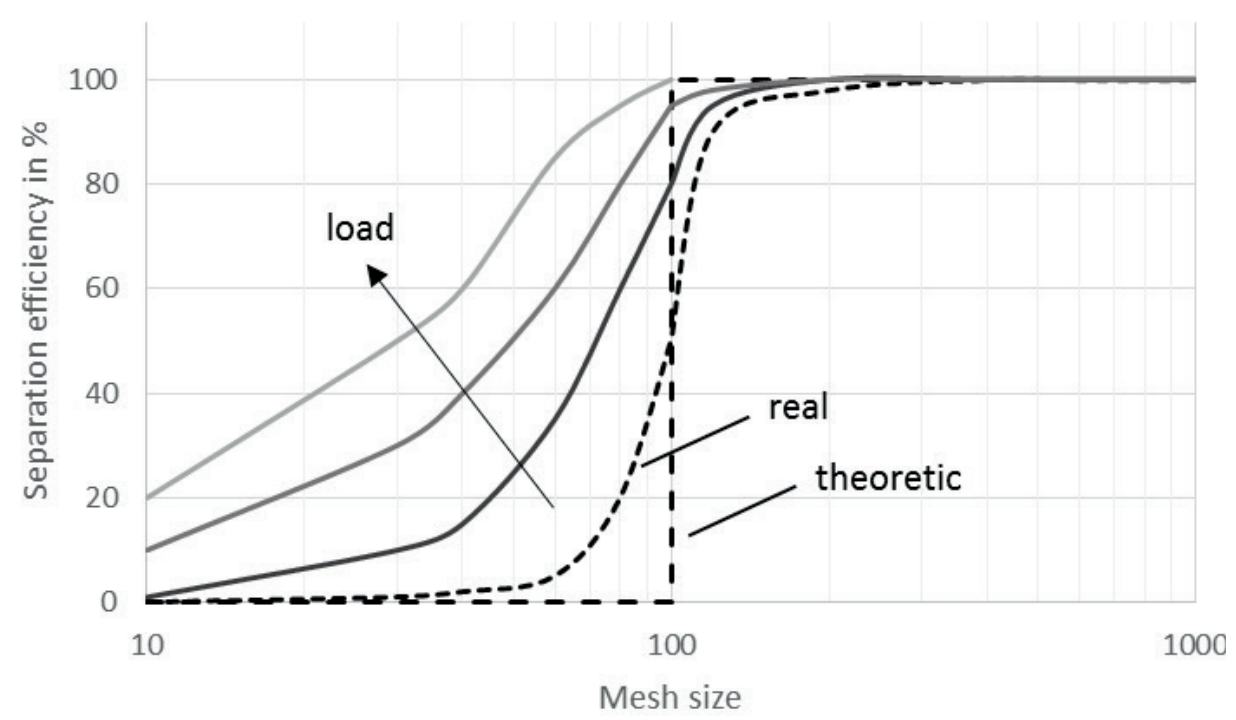

FIGURE 2: Separation efficiency curves of sieve meshes; low-dimension particle analysis is complex due to limited selectivity.

It should also be mentioned that these studies gather data from a few measurement points only and the contamination data are extrapolated to the scale of whole city areas. For example, it was calculated that 3 to 10 tons of fibres are deposited in the Parisian city region every day (R. Dris et al., 2017).

However, verification of these theoretical calculations is difficult. When dealing with measured values of the dust concentrations of airborne particles, the sampling methods are highly sensitive to differing environmental conditions. Wind, temperature, humidity, rain and even the location of the air sampler cause high fluctuation rates within the results. Furthermore, to measure very low particle concentrations (e.g., 0.3-1.5 fibres $/ \mathrm{m}^{2}$ ), extended sampling times are needed to attain a number of particles that is clearly sufficient to make any kind of statistically sound assumptions. Understandably, this results in a high level of uncertainty in the measurement. For this reason, scholars suggest that the number of measurement points and repetitions should be higher to better extrapolate results to an entire city area (Almeida et al., 2007).

\section{CRITICAL EVALUATION OF WATER SAM- PLE ANALYSIS USING SIEVES}

\subsection{Evaluation of liquid sampling using sieves}

To better illustrate the issue with these measurement techniques, the sieving operation for the samples was critically evaluated. As mentioned in the previous chapter, sieving is always the first step for analysis and it is regarded as the go-to method in the analyses of liquid samples, such as outflows of waste water treatment plants or the washing water of a commercial washing machine.

The main problem with sieving is not the method itself, but the use of inadequate mesh sizes, as already mentioned in the previous chapter, which results in a wide range of mesh sizes used, with most ranging between $20 \mu \mathrm{m}$ and $300 \mu \mathrm{m}$. Considering that the width of a fibre is typically below $10 \mu \mathrm{m}$, it is very likely that even long fibres (>40 mm) can easily pass the wider meshes. To demonstrate this, the following tests were performed.

\subsection{Materials and Methods}

\subsubsection{Materials}

- Viscose Staple Fibres

- Viscose fibres were purchased with a titer of $1.7 \mathrm{dtex}$ and a length of $40 \mathrm{~mm}$.

- Lyocell Staple Fibres

- $\quad$ Lyocell staple fibres were purchased with a titer of 1.7 dtex and a length of $40 \mathrm{~mm}$.

- Arbocel Fibre Dust

Arbocel FIC200 cellulose fibre dust was purchased, but titer and length distributions had to be determined with the MorFi optical fibre analyser due to a lack of exact specifications upon arrival. (See Figure 3)

\subsubsection{Methods}

\section{Fibre Length Adjustment}

Both the lyocell and the viscose specimen had a staple length of $40 \mathrm{~mm}$ and therefore needed to be shortened. This simulates short broken fibres as they might be found in a waste water stream. To shorten the fibres, a Hosokawa Alpine Rotoplex 20/12 RO cutting mill with $5.5 \mathrm{~kW}$ was used in conjunction with a $0.5 \mathrm{~mm}$ trapezoid cutting mill mesh and a $3 \mathrm{~mm}$ cutting mill mesh.

Three different fibre fractions were produced with this method:

$$
\begin{aligned}
& \text { - “ } 0.5 \mathrm{~mm} \text { " Lyocell } \\
& \text { - “0.5 mm" Viscose } \\
& \text { - "3 mm" Viscose }
\end{aligned}
$$

\section{Fibre Length Analysis}

To evaluate the length of the created fibre samples, an optical fibre analyser called MorFi from Techpap was used. For the analysis, a $0.2 \mathrm{~g}$ sample of the fibres to be analysed is suspended in 0.5 litre water and thoroughly mixed with a fibre mixer that is part of the MorFi measuring system. The 


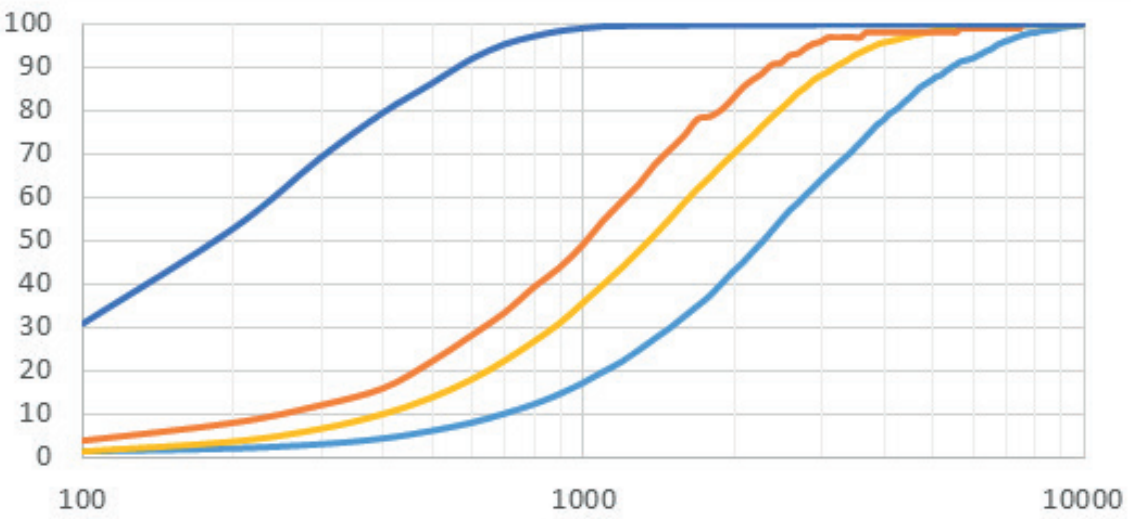

Fibre length $/ \mu \mathrm{m}$

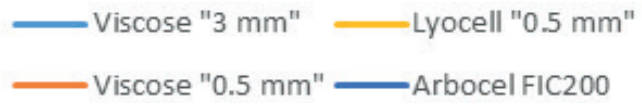

FIGURE 3: Length weighted fibre length distribution of the four samples

suspended sample is then poured into the sample reservoir of the MorFi, and the measuring device pumps the sample through a closed loop system from the reservoir back into the reservoir. While being pumped through that loop, the sample passes an optical analysis cell, where pictures of the fibres are taken. The pictures are analysed by a built-in algorithm to generate length-weighted fibre length distribution and a number-weighted fibre width distribution results. The measurements were repeated three times.

\section{Weight Analysis}

The weight of the fibre residues on the sieves was determined by first drying the whole sieve stack at $110^{\circ} \mathrm{C}$ for 24 hours and subsequently weighing each sieve with a Sartorius GP4102 laboratory scale with a maximum weight of $4100 \mathrm{~g}$ and a readability of $d=0.01$. By subtracting the dry weight of the clean sieve before the measurements, the exact fibre residue weight per fraction can be determined.

\subsection{Experiments, Results and Conclusion}

For the evaluation of the sieving procedure, fibre samples were prepared from staple cellulosic fibres, more precisely, from viscose fibres and lyocell. Additionally, Arbocel fibre dust was used to simulate very short fibre fragments. While those materials are not plastic fibres, they do have the same shape and dimensions compared to their synthetic counterparts. They are also easier to handle in a laboratory setting since they are easier to disperse in water, which is essential for accurate measurements with the MorFi. The samples were prepared by grinding the staple fibres (length approximately $40 \mathrm{~mm}$ ) in a cutting mill. By using different mesh screens within the mill, the three previously mentioned fibre samples were generated.

Before a sieving evaluation could be performed, the exact fibre length distribution of the four samples had to be determined. This was essential to being able to check which length fractions of fibres would be able to pass through a sieve with a certain mesh size. To evaluate the length of the created fibre samples, an optical fibre analyser MorFi from Techpap was used. The length-weighted fibre length distribution of the Arbocel, lyocell and the viscose samples are presented in Figure 3. The four fibre samples have very distinct distributions, with Arbocel on the shorter end with fibre lengths below $800 \mu \mathrm{m}$ and on the longer end is viscose " $3 \mathrm{~mm}$ " with fibres up to $10 \mathrm{~mm}$.

To evaluate the retention capacity of different meshes, a sieve stack containing a $25 \mu \mathrm{m}$, a $100 \mu \mathrm{m}$ and a 333 $\mu \mathrm{m}$ mesh sieve (Retsch test sieve according to ISO 3310 1) was chosen because sieves with these three mesh sizes are seemingly the most commonly used in the previously cited works. For the experiments, $10 \mathrm{~g}$ of fibres was suspended in $20 \mathrm{~L}$ of water and then slowly poured onto the sieve stack. The sieve stack was dried as a whole at $110^{\circ} \mathrm{C}$ in a climate cabinet for 24 hours until constant mass was achieved. The fibre mass deposited on every sieve was determined by weighing the corresponding sieve and subtracting the original sieve mass. The fibre lengths were measured for each fraction once again with the MorFi fibre analyser by analysing a $0.2 \mathrm{~g}$ sample of the sieve residues. This whole procedure was repeated for each of the four different fibre samples. The following distribution parameters ( $x$ values) were calculated from the data of each experiment and then combined as an average value.

In Figure 4, the average length-weighted fibre length (presented as quantiles $\times 10,1 \times 50,1$ and $\times 90,1$ ) of each fraction is shown. The $x 50,1$ represents the median length-weighted fibre length of the residue on a certain sieve. As clearly shown in the figure, these median values for all used sieves are as high as the mesh size of the respective sieve with the next-highest mesh size within the stack. The $x 90,1$ represents the share of the fibres with the highest lengths on a sieve. It shows that fibres considerably (up to ten-fold) longer than the mesh size are able to pass through a certain sieve. The $\times 10,1$ represents the 
smallest fibres within the deposited fibres on a sieve. Since these values are approximately equal to the mesh size of the respective sieves, no considerable amount of fibres with a shorter length were retained.

These results suggest that, for most cases, no fibres shorter than a certain mesh size are likely to be retained. Thus, if a collection of fibres below the evaluated mean lengths is necessary, sieves presenting mesh sizes in the respective range should be implemented.

However, already using a sieve with a mesh size of $25 \mu \mathrm{m}$, it was apparent during the experiments that the achievable flow rate is already very low; hence, a sampling of thousands of litres of water would be impossible with an even smaller mesh would be needed to sample highly diluted sources, such as waste water effluent (Murphy et al., 2016; Prata et al., 2019). Therefore, sieving with $25 \mu \mathrm{m}$ mesh size could be a good compromise between quality and quantity.

\section{HIGHLIGHTING DIFFICULTIES DURING OPTICAL ANALYSIS OF SAND SPECIMENS}

Many approaches to assess contaminants in soil or water samples are rather complex. Quite often, many steps need to be taken, and the chance for errors is high despite the efforts to avoid this issue, as has been previously stated. It is therefore advisable to lead with a straightforward method. In this regard, one possible method to obtain a fundamental idea about whether a certain level of contamination is to be expected - especially suitable for solid samples - is optical imaging analysis. This method was performed in this work for various sand specimens to highlight the difficulties in such a procedure.

\subsection{Materials}

\subsubsection{Beach sand}

The samples were taken in Sardinia next to the Forte Village Resort, the venue of the Sardina Symposium in 2017. Tidal activity is known to distribute and/or accumu- late items of various sizes across shorelines. The sampling position was defined at the mean sea water line as well as two positions with a 3 metre lateral offset to this baseline. In this fashion - and for the prevailing conditions at sampling (i.e., daylight, no rain, estimated Beaufort number 2 to 3 ) - one specimen normally without contact with the sea water, one with intermittent contact and one covered approximately full time were produced. Removing approximately $5-10 \mathrm{~cm}$ of the upper sand layer, samples of approximately $100 \mathrm{ml}$ were taken at each position with a screw-on container that was closed immediately after sampling to avoid any additional contamination. It was ensured that the water line had retired beyond the respective positions before sampling. The procedures were repeated by two experimenters.

\subsubsection{Synthetic sand mixture}

To highlight the difficulties in optical analysis of sand specimens, two synthetic sand mixtures were produced. The first mixture consisted of $10 \mathrm{~g}$ of beach sand, which was intentionally polluted with $0.1 \mathrm{~g} \mathrm{PP}$ powder $(<100 \mu \mathrm{m})$. A second sand mixture was once again prepared with 10 $\mathrm{g}$ beach sand and $0.1 \mathrm{~g}$ of pink PET microfibres ( $<1 \mathrm{dtex}$ ). Each sample mixture was intensely mixed, and a small specimen of each sample mixture was taken for optical analysis.

\subsection{Optical analysis}

An optical image analysis with a digital light microscope VHX-7000 from Keyence (magnification between 2 and 2000) was carried out after spreading $1 \mathrm{~g}$ each of the sand samples on a microscope slide. Several measurement points on the slide were chosen and investigated in detail.

The images showed that the samples had varying morphologies and colours of the granules, with mean diameters ranging from approximately $0.2-5 \mathrm{~mm}$, with a tendency to observe larger particles for the sampling positions closer to the waterline. The colour varied from transpar-

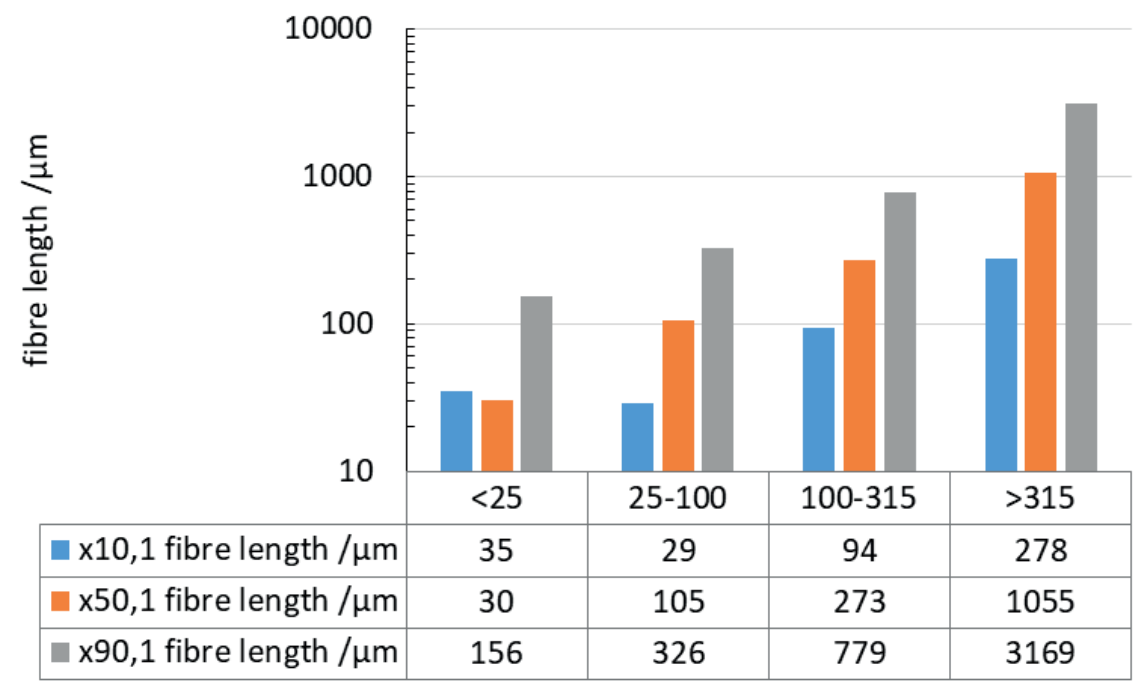

FIGURE 4: Average distribution quantiles $(x 10, x 50, x 90)$ of fibre length for different sieve fractions. 
ent-white over different shades of opaque-yellow to brown and a smaller portion of black grains (Figure 5).

At first glance, there seemed to be no contamination. However, this was only true for the samples in the millimetre size range. Upon raising magnification stepwise, every investigated sample was found to be polluted. For example, in Figure 6, two pictures show fibres surrounding small sand particles. Fibrous particles with lengths in the range of the sand particle diameters were found. These fibres had different colours and shapes, which made it possible to identify several as man-made, yet with other sample items this was ambiguous. For example, one suggestion that the fibres are of synthetic origin is the fact that the measured diameters ranged from approximately $10-30 \mu \mathrm{m}$, which is the classical order of magnitude that man-made fibres are produced to have (Sandip \& Narsingh, 2007).

It was found that spherically shaped particles below a diameter of $50 \mu \mathrm{m}$ occurred in high numbers, where colours and shapes suggested quartz particles; however, a clear differentiation was virtually impossible within this size range using optical methods only, for example, if the colours of the plastics were not easily distinguishable (pink particles, etc.). The IR method and Raman microspectroscopy (RM) could theoretically be used to identify the material; however, these methods are limited by the size of the particles $(>10 \mu \mathrm{m})$ (Schwaferts, Niessner, Elsner, \& Ivleva, 2019).

Figure 7 shows images of the synthetic sand mixtures. On the left, the mixture of PP powder with beach sand can be observed. Comparing the white PP powder with the initial sand samples, it may seem possible to distinguish the synthetic material from sand grains. However, this is only true because the size difference is known, and due to the high concentration of the PP powder, misshapen agglomerates are formed. Considering a real sample with a lower particle concentration, the distinction becomes impossible even with IR tools ("needle in a haystack").

On the right image in Figure 7, the synthetic microfibre beach sand mixture can be seen. The image shows that

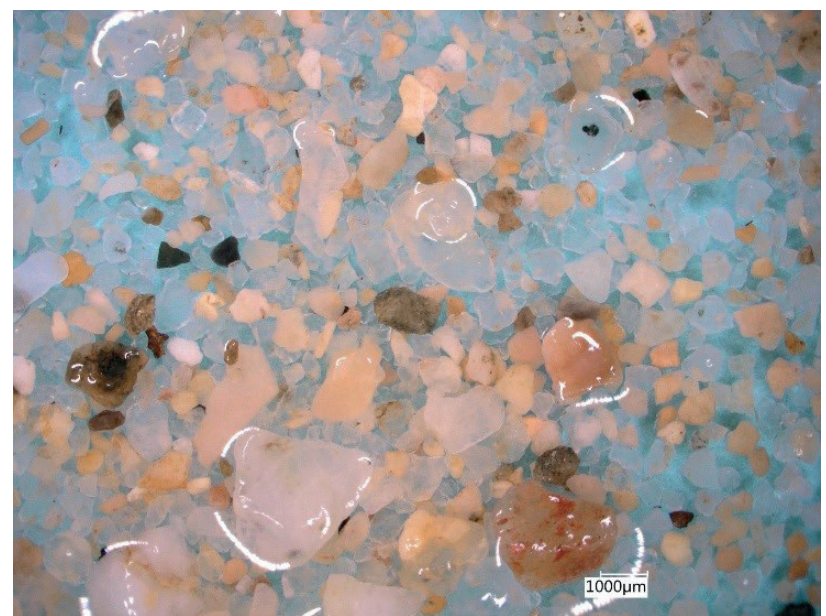

FIGURE 5: Light-microscope image of a beach sand sample drawn $3 \mathrm{~m}$ afar from mean sea water line.

fibres are clearly distinguishable from sand particles. However, the distinction between plastic fibres and natural fibrous materials is not immediately obvious. For example, in the image, the distinction between the brown fibres (organic material) and the intentionally added pink fibres is easy; however, in the case of more naturally coloured synthetic fibres, it would be more difficult to make the distinction.

Identifying synthetic fibres is easier than distinguishing between microplastic and sand because most natural fibres can be degraded by certain agents (Mai et al., 2018).

Consequently, it can be concluded that microplastic particles - in the form of short fibre residues - were already found in a rather small sample from one restricted area. Clearly, this area is not directly contrastable to areas where humans have no access. Additionally, it can be concluded that optical analysis as the sole analysis procedure is not advisable since only pronounced differences in colour, shape or size are sufficient for the correct identification of microplastics.
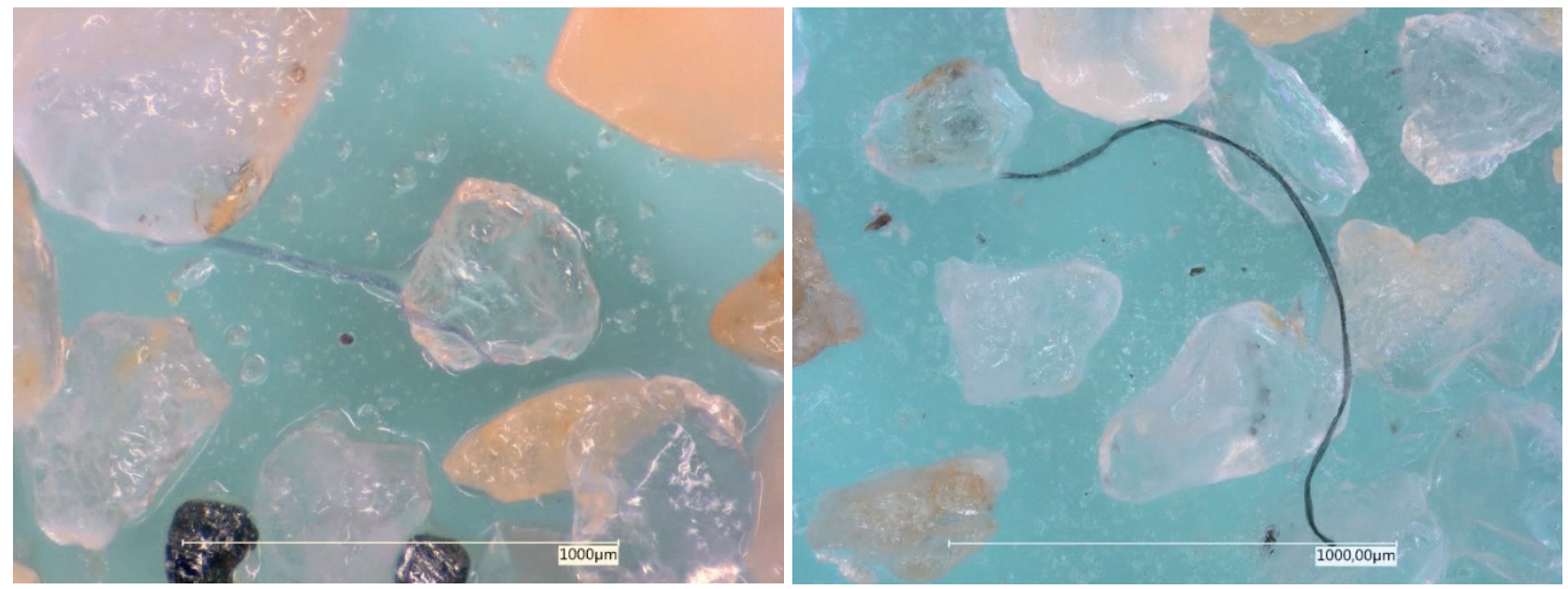

FIGURE 6: Examples of fibres found in beach sand specimen; left: coloured fibre or yarn (a twist is recognisable), right: another fibre type found. 

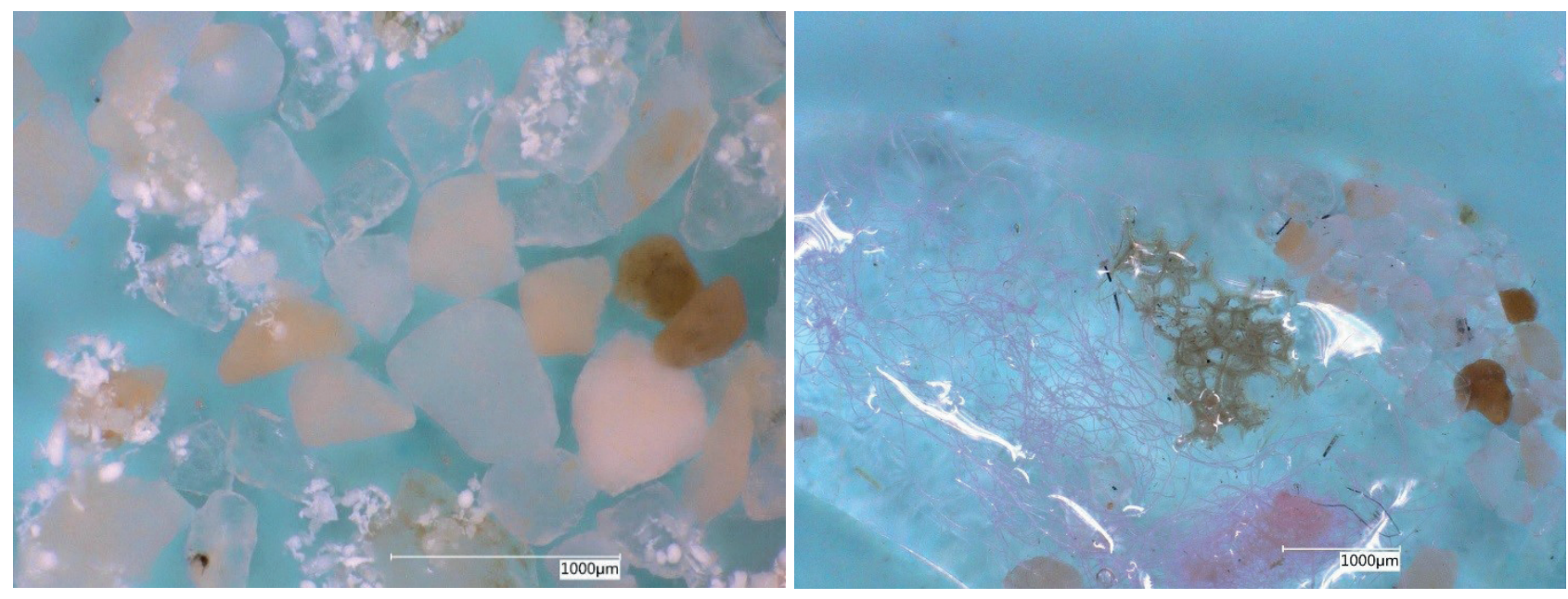

FIGURE 7: Examples of synthetic sand specimen; left: PP powder agglomerates encasing sand particles; right: PET microfibre agglomerates (pink filaments), a bundle of root or algae filaments (light brown) and unidentified black fibres.

\section{EVALUATION OF FIBRE EMISSION SOURC- ES AND PATHWAYS}

The problem of microplastics and, in particular, fibres released from textiles are currently intensively discussed. The laundering of textiles and apparel is believed to represent a major source for microfibres released into the environment (Napper \& Thompson, 2016). In principle, three routes for the release of microplastics and microplastic fibres are possible, as sketched in Figure 8.

In the figure, "route 1" means the release of fibres during the washing of clothing. It is, however, important to consider that in many industrialised countries, waste water will be supplied to a waste water treatment plant (WWTP). Recent studies show that a WWTP will remove microplastics and fibres very efficiently, whereas sewage sludge represents a sink for microplastics and fibres (Schmiedgruber, Hufenus, \& Mitrano, 2019; Sun et al., 2019). Based on this efficient cleaning of waste water, it makes little sense to use filtration systems to prevent the release of fibres from washing machines. This suggests that sewage sludge must not be applied to croplands, as microplastics and fibres will be dispersed into the environment (Corradini et al., 2019). It is further evident that the emissions of fibres from laundry into water are an issue in countries without comprehensive treatment of waste water by appropriate treatment plants. This route of fibre release into the environment will be relevant for low-income countries that cannot afford waste water treatment plants. In these countries, filtration systems for washing machines, as shown in Table 3 , would be ideal, but most likely, people cannot afford the associated acquisition and operating costs. It can even be assumed that in many developing countries, laundry will be performed in watercourses (see Figure 9); thus, filtration systems are not applicable.

As with all products, textiles and clothing will also reach the end-of-life state at a given time. Despite a separate collection and a high rate for re-use that is well established in some developed countries, a large portion will end up as municipal solid waste named as "route 2 " in Figure 8. It is evident that any uncontrolled dumping represents a potential source for microplastics and fibres. Even if waste disposal takes place in an engineered landfill, it is reported that microplastics can be found in the leachate (P. He, Chen, Shao, Zhang, \& Lü, 2019). However, in several countries, a dispersion of microplastics into the environment via solid waste will not take place for the following reasons:

- Leachates from landfills must undergo waste water treatment, and thus, microplastics and fibres will end up in the sewage sludge.

- Landfilling of waste with more than $4 \%$ total organic carbon is not allowed, which, also concerns textiles.

Finally, Figure 8 shows "route 3 " by which microplastics and microfibres might enter the environment. During use, textiles will emit fibres or fibre dust. According to the BISFA(BISFA, 2017), the terms as specified in Table 4 are defined. Recent studies show that (plastics) fibres are present in indoor as well as in outdoor environments and that these fibres represent a source for microplastics (R. Dris et al., 2017; Rachid Dris et al., 2016). Furthermore, 20 years ago, it has been proven that cellulosic and plastic fibres can be found in human lung tissue (Pauly et al., 1998).

\section{CONCLUSIONS AND OUTLOOK}

In this work, evaluation methods for microplastics were examined and tested for their applicability to detect fibre emissions. There are some major challenges to overcome in the analysis, such as the issue regarding the publication of reproducible and, most importantly, comparable results. The issue of different mesh sizes used in the sampling of waste water illustrates the problem quite vividly. While the studies using small $20-\mu \mathrm{m}$-mesh sieves detect fibres in an amount hardly even countable, other researchers using sieves with mesh sizes above $300 \mu$ m conclude that their samples are free of microplastics since nothing was retained on the used sieves. A trade-off is needed in this regard. While using sieves with mesh sizes in the single-digit micrometre range provides rather accurate re- 


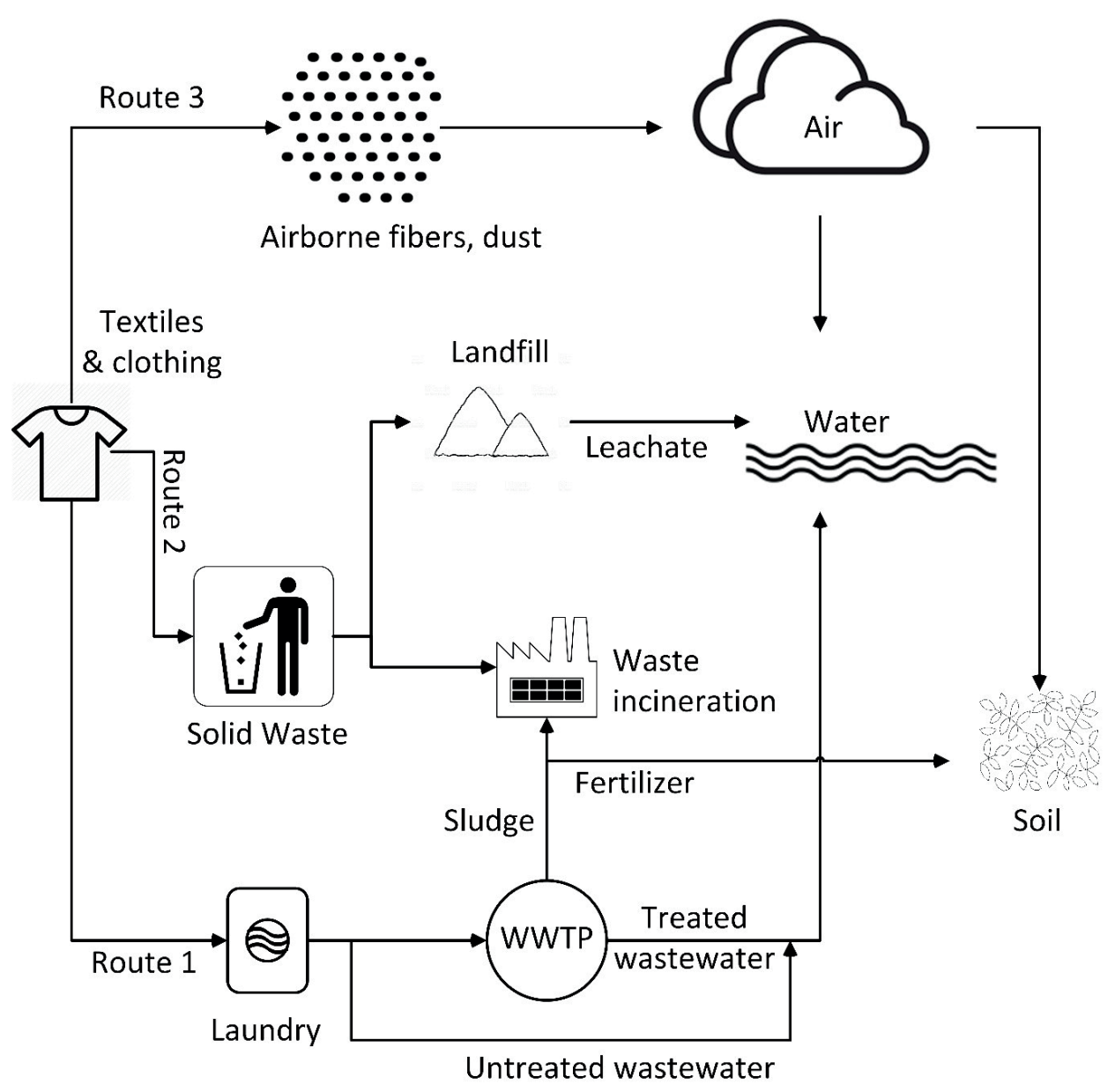

FIGURE 8: Schematic sketch of possible release of microplastics and microplastic fibers into the environment.

sults, it is impossible to analyse huge quantities of sample liquids. On the other hand, analysing vast volumes and using sieves with mesh sizes that allow most of the particles to pass through is also not very useful in most situations.

An issue that hitherto was not garnered much attention is the emission of microplastics into the air and the corresponding health risk for humans and animals. The currently available data are severely lacking, and the extrapolations from a few measurement points to whole city areas do not seem sufficiently reliable. Some studies identified fibres deep within human lung tissue, and others detected a correlation between diseases of the respiratory system and presence of high fibre concentrations in the work envi- ronment; however, no conclusive proof has been provided to correctly quantify the risks of fibre and dust.

Finally, it should be stated that while filters for washing machines and better waste water treatment plants are heavily discussed, many sources of microplastic fibres will most likely never be eliminated, for example, emissions from clothing or from the tires of cars into the air. Here, only biodegradable materials can truly stop permanent pollution of the environment with persistent substances. Many new innovative materials are being developed, but no such material has truly challenged the large competitor polyethylene terephthalate (PET), especially with respect to fibres. Highlighting this issue to the public could be the spark for a sustainable change in the sector.

TABLE 3: Selection of systems to prevent fibres to be released into the environment during laundry.

\begin{tabular}{l|l:l:l} 
Principle & Short description & Name / company & Reference \\
\hline Filter & Built-in or add-on filter for washing machine & Planet Care Limited & https://planetcare.org/en/ \\
Washing bag & Washing bag collects released microfibers during washing & Guppyfriend & http://guppyfriend.com/ \\
\hdashline Laundry ball & Laundry ball catches released microfibers during washing & Cora Ball & https://coraball.com/ \\
\hdashline Filter & Filter mounted between washing machine and drain & Filtrol 160 & https://www.septicsafe.com/ \\
\hdashline Filter & Filter mounted between washing machine and drain & Lint LUV-R & http://www.environmentalenhancements.com/ \\
\hdashline Filter & Filter mounted between washing machine and drain & Xeros' XFiltra & https://www.xerostech.com/ \\
\hline
\end{tabular}




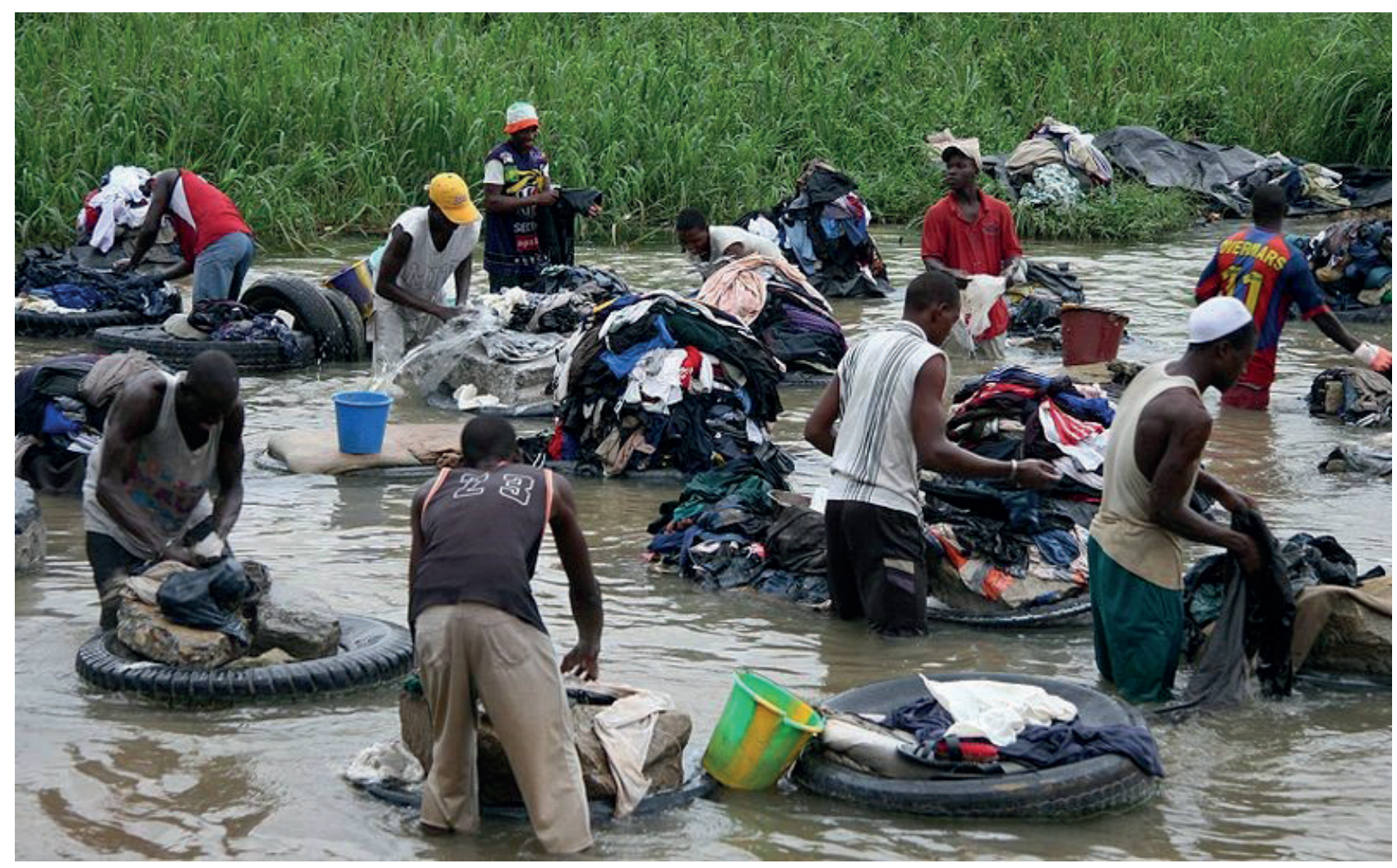

FIGURE 9: Laundry in the river Abidjan, Ivory Coast; Photo by Ferdinand Reus from Arnhem, Holland.

\section{REFERENCES}

Adam, V., Yang, T., \& Nowack, B. (2019). Toward an ecotoxicological risk assessment of microplastics: Comparison of available hazard and exposure data in freshwaters. Environ Toxicol Chem, 38(2), 436-447. doi:10.1002/etc. 4323

Almeida, S. M., Farinha, M. M., Ventura, M. G., Pio, C. A., Freitas, M. C., Reis, M. A., \& Trancoso, M. A. (2007). Measuring air particulate matter in large urban areas for health effect assessment. Water Air, and Soil Pollution, 179(1), 43-55. doi:10.1007/s11270-0069146-6

Ambrosini, R., Azzoni, R. S., Pittino, F., Diolaiuti, G., Franzetti, A., \& Parolini, M. (2019). First evidence of microplastic contamination in the supraglacial debris of an alpine glacier. Environmental Pollution. doi:https://doi.org/10.1016/j.envpol.2019.07.005

Arthur, C., Baker, J. E., \& Bamford, H. A. (2009). Proceedings of the International Research Workshop on the Occurrence, Effects, and Fate of Microplastic Marine Debris, September 9-11, 2008, University of Washington Tacoma, Tacoma, WA, USA. Retrieved from https://repository.library.noaa.gov/view/noaa/2509

Bertling, J., Hamann, L., \& Bertling, R. (2018). Kunststoffe in der Umwelt: Mikro- und Makroplastik.
BISFA. (2017). TERMINOLOGY OF MAN-MADE FIBRES. Retrieved from Brussels:

Carbery, M., O'Connor, W., \& Palanisami, T. (2018). Trophic transfer of microplastics and mixed contaminants in the marine food web and implications for human health. Environ Int, 115, 400-409. doi:10.1016/j.envint.2018.03.007

Carpenter, E. J., \& Smith, K. L. (1972). Plastics on the Sargasso Sea Surface. Science, 175(4027), 1240. doi:10.1126/science.175.4027.1240

Chemiefaser, I. (2018, June 26, 2018). Worldwide production volume of chemical and textile fibers from 1975 to 2018 (in 1,000 metric tons). Retrieved from https://www.statista.com/statistics/263154/ worldwide-production-volume-of-textile-fibers-since-1975/

Chemiefaser, I. (2019a, June 26, 2019). Global chemical fiber production from 2000 to 2018 , by fiber type (in 1,000 metric tons) Retrieved from https://www.statista.com/statistics/271651/global-production-of-the-chemical-fiber-industry/

Chemiefaser, I. (2019b, August 1, 2018). Production of polyester fibers worldwide from 1975 to 2017 (in 1,000 metric tons). Retrieved from https://www.statista.com/statistics/912301/polyester-fiber-production-worldwide/

TABLE 4: Terms for microplastics or microfibers which can be released from textile products according to BISFA 2016.

\begin{tabular}{|c|c|}
\hline Term & Description \\
\hline Fibre dust & $\begin{array}{l}\text { Non-specific terms. Can cover many types of fibrous and non-fibrous species, including contaminants, usually } \\
\text { present as mixtures of particulate matter. Recommended specific terms for airborne fibrous material are fibre } \\
\text { fly, particulates from fibres, respirable fibre-shaped particulates }\end{array}$ \\
\hline Fibre fly & airborne fibres or parts of fibres (light enough to fly), visible as fibres to the human eye \\
\hline Fibril & A subdivision of a fibre can be attached to the fibre or loose \\
\hline Particulates from fibres & $\begin{array}{l}\text { Airborne particles, not visible as fibres to the naked eye. May or may not be of the polymer material of the fibre } \\
\text { or have fibre shape under microscopic view }\end{array}$ \\
\hline Respirable fibre-shaped particulates & $\begin{array}{l}\text { Airborne particulates fulfilling the following dimensional conditions: length }>5 \mu \mathrm{m} \text { and diameter }<3 \mu \mathrm{m} \text { and } \\
\text { length/diameter ratio of }>3: 1\end{array}$ \\
\hline
\end{tabular}


Comission, E. (2011). Commission Recommendation of 18 October 2011 of the definition of nanomaterial (2011/696/EU). Official Journal of the European Union, 54, 38-40.

Corradini, F., Meza, P., Eguiluz, R., Casado, F., Huerta-Lwanga, E., \& Geissen, V. (2019). Evidence of microplastic accumulation in agricultural soils from sewage sludge disposal. Science of The Total Environment, 671, 411-420. doi:https://doi.org/10.1016/j.scitotenv.2019.03.368

Council, N. C. (2018, August 1, 2018). Global cotton production volume from 1990 to 2018 (in 1,000 bales). Retrieved from https:// www.statista.com/statistics/259392/cotton-production-worldwide-since-1990/

Dris, R., Gasperi, J., Mirande, C., Mandin, C., Guerrouache, M., Langlois, V., \& Tassin, B. (2017). A first overview of textile fibers, including microplastics, in indoor and outdoor environments. Environ Pollut, 221, 453-458. doi:10.1016/j.envpol.2016.12.013

Dris, R., Gasperi, J., Saad, M., Mirande, C., \& Tassin, B. (2016). Synthetic fibers in atmospheric fallout: A source of microplastics in the environment? Marine Pollution Bulletin, 104(1), 290-293. doi:https:// doi.org/10.1016/j.marpolbul.2016.01.006

Eyerer, P., Hirth, T., \& Elsner, P. (2008). Polymer Engineering: Springer-Verlag Berlin Heidelberg.

Fisher, J. W., Hogan, J. A., Delzeit, L., Liggett, T., Wignarajah, K., Alba, R., . . Fox, T. G. (2008). Waste Management Technology and the Drivers for Space Missions. In: SAE International

Gasperi, J., Wright, S. L., Dris, R., Collard, F., Mandin, C., Guerrouache, M., ... Tassin, B. (2018). Microplastics in air: Are we breathing it in? Current Opinion in Environmental Science \& Health, 1, 1-5. doi:10.1016/j.coesh.2017.10.002

GESAMP. (2015). Sources, fate and effects of microplastics in the marine environment: a global assessment. Retrieved from

Hantoro, I., Lohr, A. J., Van Belleghem, F., Widianarko, B., \& Ragas, A. M. J. (2019). Microplastics in coastal areas and seafood: implications for food safety. Food Addit Contam Part A Chem Anal Control Expo Risk Assess, 36(5), 674-711. doi:10.1080/19440049.2019.1 585581

Hartline, N. L., Bruce, N. J., Karba, S. N., Ruff, E. O., Sonar, S. U., \& Holden, P. A. (2016). Microfiber Masses Recovered from Conventional Machine Washing of New or Aged Garments. Environ Sci Technol, 50(21), 11532-11538. doi:10.1021/acs.est.6b03045

He, D., Luo, Y., Lu, S., Liu, M., Song, Y., \& Lei, L. (2018). Microplastics in soils: Analytical methods, pollution characteristics and ecological risks. TrAC Trends in Analytical Chemistry, 109, 163-172. doi:https://doi.org/10.1016/j.trac.2018.10.006

He, P., Chen, L., Shao, L., Zhang, H., \& Lü, F. (2019). Municipal solid waste (MSW) landfill: A source of microplastics? -Evidence of microplastics in landfill leachate. Water Research, 159, 38-45. doi:https://doi. org/10.1016/j.watres.2019.04.060

Hidalgo-Ruz, V., Gutow, L., Thompson, R. C., \& Thiel, M. (2012). Microplastics in the Marine Environment: A Review of the Methods Used for Identification and Quantification. Environmental Science \& Technology, 46(6), 3060-3075. doi:10.1021/es2031505

Kusters, K. A., Pratsinis, S. E., Thoma, S. G., \& Smith, D. M. (1993). Ultrasonic fragmentation of agglomerate powders. Chemical Engineering Science, 48(24), 4119-4127. doi:https://doi.org/10.1016/00092509(93)80258-R

Liebmann, B. (2015). Mikroplastik in der Umwelt - Vorkommen, Nachweis und Handlungsbedarf. In: Umweltbundesamt $\mathrm{GmbH}$.

Mai, L., Bao, L. J., Shi, L., Wong, C. S., \& Zeng, E. Y. (2018). A review of methods for measuring microplastics in aquatic environments. Environ Sci Pollut Res Int, 25(12), 11319-11332. doi:10.1007/ s11356-018-1692-0

Miele. (2019). Operating instructions for condenser dryers M.-Nr. 09 938 570. Retrieved from https://www.miele.co.uk/pmedia/ZGA/ TX2070/9938570-000-02_9938570-02.pdf

Miklos, D., Obermaier, N., \& Jekel, M. (2016). Mikroplastik: Entwicklung eines Umweltbewertungskonzepts. Retrieved from Dessau-Rosslau:

Murphy, F., Ewins, C., Carbonnier, F., \& Quinn, B. (2016). Wastewater Treatment Works (WWTW) as a Source of Microplastics in the Aquatic Environment. Environ Sci Technol, 50(11), 5800-5808. doi:10.1021/acs.est.5b05416

Napper, I. E., \& Thompson, R. C. (2016). Release of synthetic microplastic plastic fibres from domestic washing machines: Effects of fabric type and washing conditions. Mar Pollut Bull, 112(1-2), 39-45. doi:10.1016/j.marpolbul.2016.09.025
Park, T. (2016). Microbeads: How did companies respond? Retrieved from http://www.greenpeace.org/eastasia/news/blog/microbeads-how-did-companies-respond/blog/57339/

Pauly, J., Stegmeier, S., Allaart, H., Cheney, R., Zhang, P., Mayer, A., \& Streck, R. (1998). Inhaled cellulosic and plastic fibers found in human lung tissue. Cancer Epidemiol Biomarkers Prev, 7(5), 419-428.

Pirc, U., Vidmar, M., Mozer, A., \& Krzan, A. (2016). Emissions of microplastic fibers from microfiber fleece during domestic washing. Environ Sci Pollut Res Int, 23(21), 22206-22211. doi:10.1007/ s11356-016-7703-0

Pivokonsky, M., Cermakova, L., Novotna, K., Peer, P., Cajthaml, T., \& Janda, V. (2018). Occurrence of microplastics in raw and treated drinking water. Science of The Total Environment, 643, 1644-1651. doi:https://doi.org/10.1016/j.scitotenv.2018.08.102

PlasticsEurope. (2018). Plastics - the Facts 2018. Retrieved from Wemmel - Belgium: https://www.plasticseurope.org/download_ file/force/1055/319

Prata, J. C. (2018). Airborne microplastics: Consequences to human health? Environmental Pollution, 234, 115-126. doi:https://doi. org/10.1016/j.envpol.2017.11.043

Prata, J. C., da Costa, J. P., Duarte, A. C., \& Rocha-Santos, T. (2019). Methods for sampling and detection of microplastics in water and sediment: A critical review. TrAC Trends in Analytical Chemistry, 110, 150-159. doi:https://doi.org/10.1016/j.trac.2018.10.029

Rochman, C. M. (2015). The Complex Mixture, Fate and Toxicity of Chemicals Associated with Plastic Debris in the Marine Environment. In M. Bergmann, L. Gutow, \& M. Klages (Eds.), Marine Anthropogenic Litter (pp. 117-140). Cham: Springer International Publishing

Sandip, V. P., \& Narsingh, R. P. (2007). Microfibres, Microfilaments and their applications. AUTEX Research Journal, 7(3).

Schmiedgruber, M., Hufenus, R., \& Mitrano, D. M. (2019). Mechanistic understanding of microplastic fiber fate and sampling strategies: Synthesis and utility of metal doped polyester fibers. Water Research, 155, 423-430. doi:https://doi.org/10.1016/j. watres.2019.02.044

Schwaferts, C., Niessner, R., Elsner, M., \& Ivleva, N. P. (2019). Methods for the analysis of submicrometer- and nanoplastic particles in the environment. TrAC Trends in Analytical Chemistry, 112, 52-65. doi:https://doi.org/10.1016/j.trac.2018.12.014

Sular, V., \& Devrim, G. (2019). Biodegradation Behaviour of Different Textile Fibres: Visual, Morphological, Structural Properties and Soil Analyses. Fibres and Textiles in Eastern Europe, 27, 100-111. doi:10.5604/01.3001.0012.7751

Sun, J., Dai, X., Wang, Q., van Loosdrecht, M. C. M., \& Ni, B.-J. (2019) Microplastics in wastewater treatment plants: Detection, occurrence and removal. Water Research, 152, 21-37. doi:https://doi. org/10.1016/j.watres.2018.12.050

Talvitie, J., Mikola, A., Koistinen, A., \& Setala, O. (2017). Solutions to microplastic pollution - Removal of microplastics from wastewater effluent with advanced wastewater treatment technologies. Water Res, 123, 401-407. doi:10.1016/j.watres.2017.07.005

Talvitie, J., Mikola, A., Setala, O., Heinonen, M., \& Koistinen, A. (2017). How well is microlitter purified from wastewater? - A detailed study on the stepwise removal of microlitter in a tertiary level wastewater treatment plant. Water Res, 109, 164-172. doi:10.1016/j. watres.2016.11.046

Textor, T., Derksen, L., Bahners, T., Gutmann, J. S., \& Mayer-Gall, T. (2019). Abrasion resistance of textiles: Gaining insight into the damaging mechanisms of different test procedures. Journal of Engineered Fibers and Fabrics, 14, 1558925019829481. doi:10.1177/1558925019829481

Thompson, R. C., Olsen, Y., Mitchell, R. P., Davis, A., Rowland, S. J., John, A. W. G., . . . Russell, A. E. (2004). Lost at Sea: Where Is All the Plastic? Science, 304(5672), 838. doi:10.1126/science.1094559

US Environmental Protection Agency. (1982). Handbook for Sampling and Sample Preservation of Water and Wastewater. Cincinetti, Ohio: BiblioGov.

Ziajahromi, S., Neale, P. A., Rintoul, L., \& Leusch, F. D. (2017). Wastewater treatment plants as a pathway for microplastics: Development of a new approach to sample wastewater-based microplastics. Water Res, 112, 93-99. doi:10.1016/j.watres.2017.01.042 